\title{
A Brief History of the Pick Environment in Australia
}

\author{
Stasys Lukaitis \\ School of Business Information Technology RMIT Melbourne Australia \\ stasys.lukaitis@rmit.edu.au
}

\begin{abstract}
Mainstream Information Technology professionals have misunderstood the Pick environment for many years. The Pick environment has been conceived, designed and built with business solutions as its key driver. At its heyday there were over 3,000 business applications available across a very wide range of hardware platforms supporting from 1 to thousands of real time users. The tentative economic recovery of the 90's and the Y2K fears created cautious and conservative corporate decision-making. During those tumultuous years there were startling leaps in information and communications technology rewarding those who invested in the future and in themselves. The Pick community at the time were fragmented and somewhat narrow-minded in their view of the future and were unable to collectively invest in developing new technologies. Corporate executive peer group pressure to adopt "vanilla" relational technologies and the desire for homogeneity is creating even more pressure on the Pick community.
\end{abstract}

Keywords: Pick; Universe; Unidata; Prime; Revelation; jBase; Reality; Multivalue; Correlative; D3.

\section{Introduction}

A simple Google search for the PICK environment or database will reveal a plethora of information about the history of the Pick Operating System and DBMS over the years. It is not the intention of this paper to repeat what is already freely available. Suffice it to say that PICK was 'invented' in the USA by Richard (Dick) Pick and Don Nelson as contractors for TRW on the Cheyenne Helicopter parts and maintenance project. The Appendix shows the various incarnations of the product as well as its early entry into Europe through Microdata Intertechnique in France.

This paper seeks to highlight an interesting historical period in the development of Information and Communications Technology in Australia and to notice the various influences of (then) emerging factors on the Information Systems that were in use at that time, and the Pick environment as an interesting example. The period under investigation is the last two decades of the twentieth century 1980-2000, with the emphasis on the early 1990s and the period approaching the Y2K event.

\subsection{Research Approach}

Thus this is a hermeneutical analysis of a brief period in Australian IT history using the Pick environment as the driver. Hermeneutics is a philosophy of enquiry that 
seeks to gain understanding about an issue or question using techniques that attempt to deal with a researcher's biases and prejudices, and in particular the effects of historicality $^{1}$ - not taking into consideration the historical milieu and social events and thinking of the time, and the way that language and its use and interpretations can colour understanding and interpretation [1].

In this usage of hermeneutics I use original documents in the form of books, reports, magazines, articles, quotations from the industry leaders of the time and personal experience. The reason for the use of the hermeneutic philosophy is to glean understanding of the historical milieu from a variety of data sources.

This research will review the "forgotten factors" of the time, the drivers that pushed the Australian IT industry, the key decision makers and what was happening to technology then. Historical investigations such as this should be free from the emotion and biases because, as Gadamer stated, the passage of time has allowed the events to be "closed" [2].

The Pick environment in the first decade of the twenty-first century has become a little more obscure than during its heyday in the latter part of the twentieth century, and this article might shed some light and perhaps some useful debate on the issue. The understanding and appreciation of history in its unsanitised form can be helpful in avoiding mistakes and errors already committed. It is a fact that with "all histories they are the tales of the winners who always rewrite history to their image, leaving many stories untold" [3].

\section{Brief Overview of the "PICK" Concept}

Without experience in the Pick environment it was easy to be confused at the time as to what Pick actually was. Mostly it was believed that Pick was just an operating system with some sort of database management system also called Pick. Operating systems in the 1970s and 1980s were mostly proprietary and non-portable between hardware platforms. As an example, HP minicomputers were released with a proprietary operating system called MPE-IV (1980's) [4] that only worked on HP manufactured equipment. Similar examples existed with IBM and DEC (VMS).Open systems were emerging and one called Unix was starting to be seen available on several different hardware platforms. This portability was exciting the ICT community at the time because being tied to a particular hardware vendor was seen as undesirable for many reasons, one of which was being locked into a scalability ceiling ${ }^{2}$. IBM was famous at that time by offering relatively continuous scalability solutions right through to their mainframe systems. This section briefly outlines the Pick environment from four perspectives of a) the data model; b) the operating system; c) applications development environment; and d) the data retrieval model. Readers interesting a more thorough explanation of this environment are referred to the bibliography for a range of material.

\footnotetext{
${ }^{1}$ Historicality: A term coined by Hans Georg Gadamer to describe the effect of time and cultural distance between the investigator and that being investigated. An example might be the difficulty in understanding life in ancient Rome from the perspective of a 21 st century Los Angeles dweller.

${ }^{2}$ Scalability ceiling: Reaching the performance limits of the hardware/operating systems platform and being unable to sensibly expand beyond that capability.
} 


\subsection{The Data Model}

The actual database was modeled as a "Hashed Indexed Sequential Access Method" (HSAM) mechanism. Each data record was indexed by a unique primary key that is used to calculate which frame (or bucket) is its home location inside a given fixedsize file. So for a given file and frame the read and write commands "compiled" directly to an absolute disk, head and sector address.

Unlike other data models Pick's record structure is not predetermined by a Data Definition Language. Traditionally a database is created with the required number of tables, each table having its own peculiar structure. In Pick, one created files as

Table 1. Student Record Layout in Pick

\begin{tabular}{|l|l|}
\hline Attribute \# & Data \\
\hline $0 . .11$ & Traditional fields student ID, names, addresses, sex, phone numbers, DOB \\
\hline 12 & Subject code (text)(MV Controlling)(Associated to file Subjects) \\
\hline 13 & Semester code enrolled (text)(MV Dependent \#12) \\
\hline 14 & Result (number)(MV Dependent \#12) \\
\hline 15 & $\begin{array}{l}\text { Assignment result(s)(MV Dependent \#12)(Multi-sub-valued- multiple assignment } \\
\text { results allowed) }\end{array}$ \\
\hline $16 \ldots$ & More attributes \\
\hline
\end{tabular}

When we look at an actual record, it might be represented like this ...

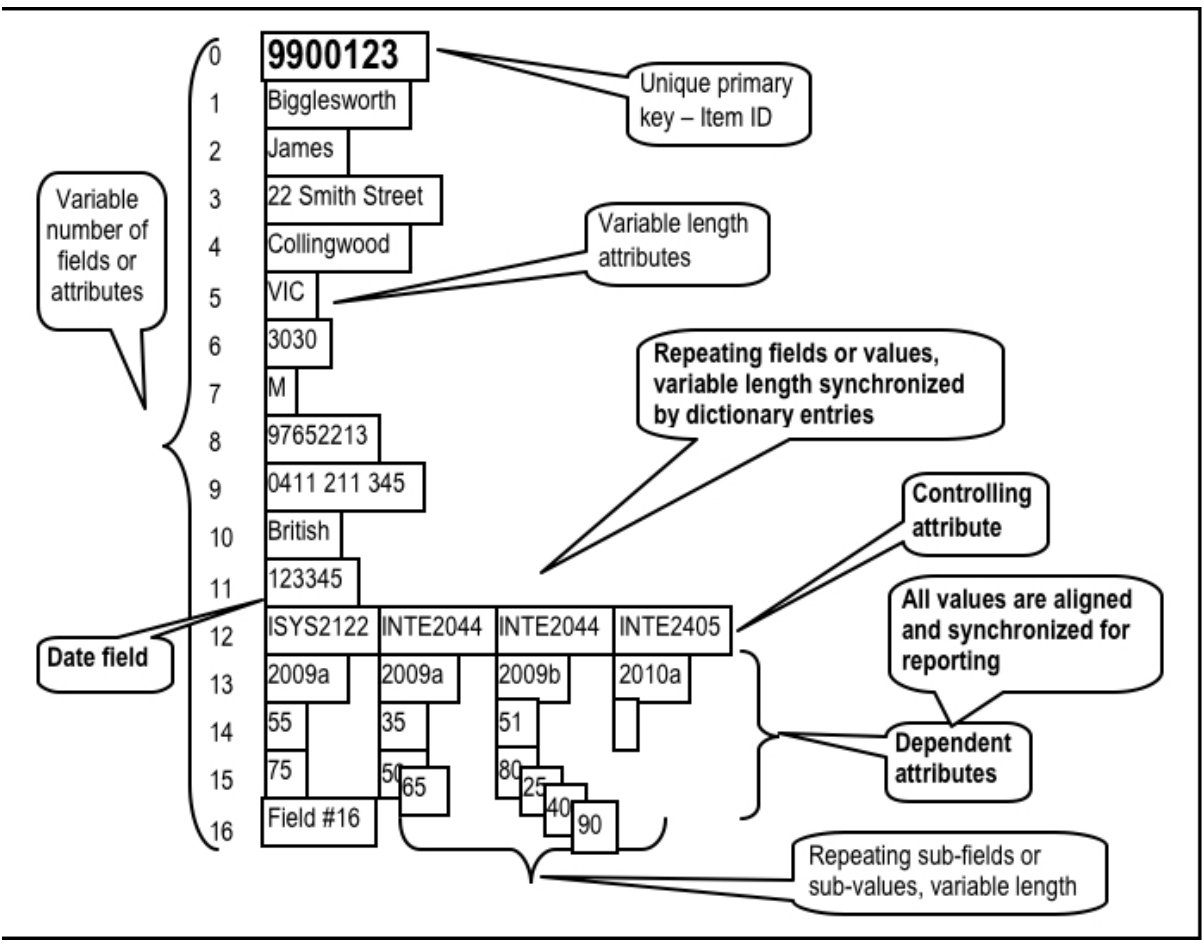

Fig. 1. Representation of a Student Record 
needed, each one equivalent to a table. The database was then all the files that were related. Typically one would create an account called "Student Records" and all the related files would be stored there.

Pick differs from other database models because it allows fields to have repeating values and for one field to be a "controlling" field with others defined as "dependent" fields. This allows synchronization of repeating fields. It is also possible for any of these individual repeating fields to themselves store repeating "sub-fields".

Whereas people using the relational model must normalize their structures, the Pick model allows avoiding first normal form and the consequential join tables. Look at the example of a student database that stores student data as well as multiple subjects studied and as well as results for multiple assignments for each subject.

The repeating fields at 12,13,14 and 15 break Codd's 1 NF law but allow this repeating data to be stored inside the original record instead of creating an additional table that will need to be 'joined back' later when accessed. Attribute 15 holds repeating sub-values aligned to the controlling attribute 12 . Here we are able to model assignment results for a given subject where there might be a varying number of assignments for each subject and even varied according to the semester taken.

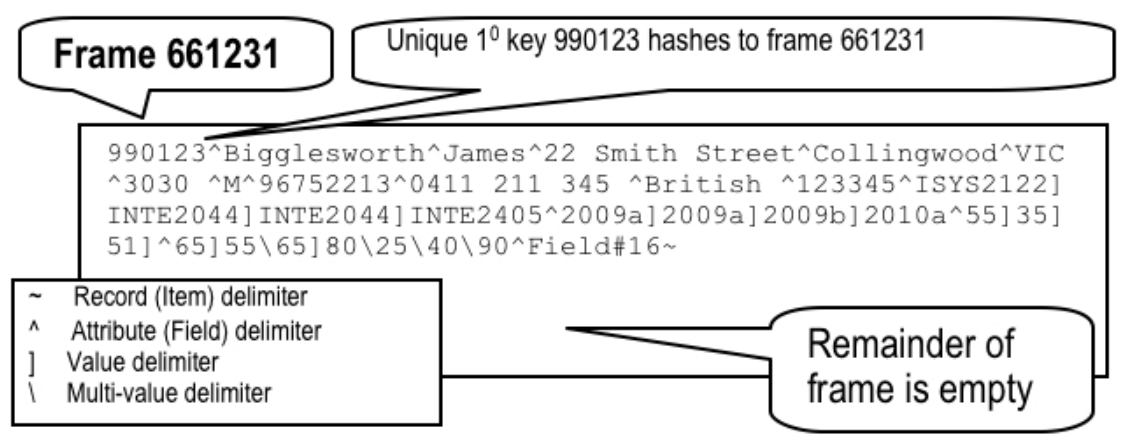

Fig. 2. Example of the Actual Data Record on Disk that is Read and Written

Thus one of the key differentiators of the Pick data model is that each "master record" can also contain all the detail elements associated with transactions on that record. In the example shown, the one structure has replaced several relational tables, or indeed several network-based DBMS detail files. This is quite a saving in not only potential disk space but more importantly in the disk I/O necessary to perform queries and updates.

\subsection{The Operating System Model}

There was a stranglehold by the major vendors on their proprietary hardware and attached host operating systems. IBM, HP and DEC were but a few of the major players. It is now of historical interest the difficulties that IBM found themselves in with OS360 described by Brooks [5]. The Pick operating system was multi-user and timesharing with the ability to run dozens of serial users on an Intel 486 computer with 
512k RAM and an RS232 expansion card. Pick was an early implementer of code reentrancy which enabled efficient working set management to be implemented [6].

Perhaps from the Pick perspective, two important events were the release of the RISC engine as popularised by the Motorola M68x and IBM RS6x series chipsets and the implementation of SCSI hard disk technology which allowed very fast disk access. Pick was ported to the M68xx chipset and arrived in Australia as the Wicat computer. This was one of many ports of the operating system.

\subsection{Applications Development Environment}

The applications development environment was implemented with a programming language that was tightly integrated to the host operating system and the database management system. The language syntax included very sophisticated string manipulation capabilities and dynamic arrays that mimicked and implemented the database's fundamental record structure, and internal conversion routines that allowed quite advanced date and time manipulation.

Specialised syntax allowed rapid read/write access to any files that your security level allowed. You could read an individual record or even fields within that record. Locks could be applied on a record to prevent file integrity problems surfacing in a multi-user environment to the degree where an optimistic locking strategy could be programmed to avoid a race condition and ultimate deadlock occurring.

The language compiled to a $\mathrm{p}-\operatorname{code}^{3}$ that was remarkably efficient in a multi-user environment and later into native chipset executable code which increased execution speed markedly. It supported run-time relocation of subroutine code. This was keenly exploited by programmers storing the names of candidate subroutines in files that were read during program execution and loaded and run according to state conditions. Recursion was also supported, although not greatly used as it (still) is a dangerous tool in the hands of any novice programmer.

Most Pick developers were conscious of the power in the programming environment and took appropriate precautions. Nevertheless, as Dick Pick was once quoted as saying that his system was replete with features he called "rope". There was plenty there with which to hang yourself [7].

The only problem with this development environment and language was its name Pick/BASIC. Most developers in the Pick community thought nothing of its name, but were constantly embroiled in bickering about the language with non-Pick developers who imagined it to be a form of Dartmouth Basic.

\subsection{Query and Reporting Language Environment}

The query language, called ACCESS, used against a given file would be driven by the data dictionary associated with that file. In other words, using the student record example earlier, you could readily query the student file for reports or information from the target file name (student) and the list of fields (dictionary definitions) in which you were interested. This is consistent with most modern query languages such as SQL. Unlike modern day SQL, Pick ACCESS is strictly a reporting language.

\footnotetext{
${ }^{3}$ P-Code. Pseudo code. A code that was not unlike assembler, but was interpreted at runtime by the internal Pick OS engine, not a p-code compiler.
} 


\subsection{Diversity}

There were numerous implementations of the model from traditional Pick (OS, programming language and DBMS) through to jBase (Unix, Linux or MS Windows OS, any DBMS and any language but still including Basic). Appendix 1 illustrates the development of the environment in its three streams - the traditional Pick "R83", the Microdata Reality branch and the Prime Information/U2 branch. Today there are several implementations of this Pick model and depending on your scale and communications needs, there will be several implementations from which a good choice could be made.

\section{The 1980s and 1990s Context}

\subsection{Database Choices}

In those early days of databases there were a couple of choices of database model. Indexed Sequential Access Model (ISAM) databases were the most popular amongst the larger machines and were used by IBM in their offerings and made "famous" by the leading database writers of the time like James Martin [8]. The other popular database model at the time was the network model, a precursor to the relational model of today. This was popular amongst mini-computer vendors typified by Hewlett Packard and the IMAGE databases [9].

Finally, the iconic Ted Codd published a number of papers describing the twodimensional relational database model, based on predicate logic and a relational algebra and calculus [10-12]. Numerous implementations of this relational database were spawned with some examples being DB2, Informix, Ingres, Sybase, Unify, Progress, Oracle (various hardware platforms) and later, some Open Source Unix implementations such as PostreSQL and MySQL ${ }^{4}$.

\subsection{Universities' Impact}

Universities around the world became enamoured of the possibilities of a DBMS that was based on a mathematical model. This was understandable as many computer science departments were born from mathematics schools [13].

Database courses were taught in Universities at the time used the popular book by Tsichritzis (Data Models) [14] that identified three main data models - the relational, network and hierarchical models and further treated on the E- $\mathrm{R}^{5}$, Binary, Semantic and Infological models. These were the only models taught.

\subsection{Centralised IT Dissatisfaction}

Mainframes were becoming increasingly unpopular because of the hold by $\mathrm{DP}^{6}$ departments on business applications development (COBOL, PL/I, RPGII, etc) and delays and errors in delivery of systems. Anecdotal evidence at the time estimated the

\footnotetext{
${ }^{4}$ MySQL: Bought out by Sun Microsystems which is now owned by Oracle.

${ }^{5}$ E-R: Entity Relationship data model.

${ }^{6}$ DP: Data Processing departments as they were known at that time.
} 
applications development lead time to be about 4 years. The inability of centralized DP departments to provide satisfactory service levels (sic) led to local "Departmental" solutions leveraging off the emergence of the new mini-computers. Many of these solutions were sourced from enterprising companies who could see the need for bureaus, a service that companies or Departments could buy to solve pressing IT problems.

\subsection{Microcomputers and Applications}

Visicalc ${ }^{7}$ empowered the accounting fraternity with the ability to create complex budgets and perform "what if" scenarios. This released accountants from the control of their DP groups and mainframe-based computer financial models and gave them the independence to plan, model and forecast without the constant DP engagement.

The word processor and "Windows" desktops heralded workstation ubiquity and the death of the beloved typing pool and the start of end-user computing. The "electronic office" was coined and a "paperless office" was promised.

\subsection{The Internet}

The second thing after PCs and VisiCalc was international data communications, Usenet and email. In hindsight this event created the birth of the global village. By subscribing to your local ISP of the time you could plug into the wisdom of thousands of savants and exchange electronic mail with them and others instantly. Back in the 1980's some quite serious problems could be tackled by joining the appropriate user group and taking a few tentative steps in asking for help. Like today's Wikipedia and Web2.0 the newsgroups were dominated by the loudest and most shrill voices and those with the most apparent authority. It is not surprising then that many vendors spent considerable budget ensuring that their message was being received loud and clear.

\subsection{Point and Click Paradigm}

In the middle 1990's the web browser was invented to take advantage of something called hypertext and HTML became the way to browse online information. A pleasantly crafted windows environment with mouse-based point and click browsing became the dominant paradigm for interacting with the now ubiquitous desktop PC and MAC. New forms of data entry exploded with radio buttons, pull down menus, check boxes, and of course hyperlinks, all driven by the mouse as the locating tool.

Products such as Visual Basic, "Powerbuilder" and "Oracle Forms" enabled this windows paradigm to be extended into database interaction and transaction processing environments. So it thus became the dominant user interface paradigm - windows, point and click, buttons, boxes and pull-downs, an entire event driven environment. HTML extended it to include hyperlinks.

\subsection{Australian SMEs}

Because of simple scale factors, Australia had a lot of small to medium enterprises (SMEs) for whom mainframe solutions were inappropriate and who might have

\footnotetext{
${ }^{7}$ And later and more ubiquitous was LOTUS-123.
} 
turned to a bureau solution. The new mini-computers [15-16] became attractive options and were actively pursued. Companies whose IT was agile enough to "move with the times" often gained significant competitive advantage by simply having the better IT solutions of their competitors.

Examples of this were the burgeoning Credit Union movement in Australia, sophisticated Insurance and Library solutions, and very popular manufacturing and distribution systems reminiscent of the original TRW product and precursors to the MRP and MRP-II ${ }^{8}$ products.

\subsection{The Pick Community in 1992}

Australia had several State-based Pick User Groups active in 1992 and most were called the "International Pick Users Association" (IPUA). The Melbourne group was active and hosted several conferences called PickLab from 1988 till 1994. The 1992 conference attracted several overseas dignitaries and featured prominently in the international press [17].

Local and international Pick identities were canvassed in 1992 to offer their opinions on the future of the Pick marketplace. Table summarises their views.

Table 2. Leading Australian Pick Identities Views on Pick's Future

\begin{tabular}{|c|c|c|}
\hline Identity & Company & Views \\
\hline $\begin{array}{l}\text { Peter } \\
\text { Fenwick }\end{array}$ & $\begin{array}{l}\text { Fenwick } \\
\text { Software }\end{array}$ & $\begin{array}{l}\text { Pick's future is rosy because of its acceptance of Unix (Open Systems) as } \\
\text { a host operating system. Pick is far more efficient than its competitors so } \\
\text { one can run more users on equivalent hardware [18]. }\end{array}$ \\
\hline $\begin{array}{l}\text { Rob } \\
\text { Coulson }\end{array}$ & $\begin{array}{l}\text { Idealogy } \\
\text { Systems }\end{array}$ & $\begin{array}{l}\text { Unix as the host operating system is inevitable and needs to be adopted. } \\
\text { Pick's success will be driven by its breadth of applications [19]. }\end{array}$ \\
\hline $\begin{array}{l}\text { Terry } \\
\text { Leister }\end{array}$ & $\begin{array}{l}\text { VMark Asia } \\
\text { Pacific }\end{array}$ & $\begin{array}{l}\text { Unix is the host operating system of the future. Pick needs to accept new } \\
\text { technologies such as client-server models and allow processing to be done } \\
\text { on the desktop. GUI such as X-Terminals is needed [20]. }\end{array}$ \\
\hline $\begin{array}{l}\text { Tom } \\
\text { Couvret }\end{array}$ & $\begin{array}{l}\text { Prime } \\
\text { Computer }\end{array}$ & $\begin{array}{l}\text { The key to success will be standards, portability between platforms, } \\
\text { communications, distributed databases and desktop integration [21]. }\end{array}$ \\
\hline $\begin{array}{l}\text { Al Dei } \\
\text { Maggi }\end{array}$ & $\begin{array}{l}\text { Sequent } \\
\text { Computer } \\
\text { Systems }\end{array}$ & $\begin{array}{l}\text { Pick's future depends on it ability to integrate with dominant industry } \\
\text { standard software layers and systems such as Oracle. Commitment to } \\
\text { supporting advanced GUIs and intelligent desktop integration [22]. }\end{array}$ \\
\hline $\begin{array}{l}\text { Charles } \\
\text { Cave }\end{array}$ & $\begin{array}{l}\text { Unidata } \\
\text { Australia }\end{array}$ & $\begin{array}{l}\text { Adherence and support of Open Systems standards like SQL, TCP/IP } \\
\text { X.25 and X11 based GUIs. Integration with products such as Framemaker } \\
\text { (publishing), WordPerfect and various graphical applications [23]. }\end{array}$ \\
\hline $\begin{array}{l}\text { Tim } \\
\text { Cianchi }\end{array}$ & $\begin{array}{l}\text { Apscore } \\
\text { International }\end{array}$ & $\begin{array}{l}\text { Pick cannot survive in its current form. New object oriented technology } \\
\text { will sweep everything away in the next } 5-10 \text { years. In the short term Open } \\
\text { Systems compliance, integration with desktop applications and adoption } \\
\text { of three tier architectures [24]. }\end{array}$ \\
\hline $\begin{array}{l}\text { Mike } \\
\text { Ferris }\end{array}$ & UniPix & $\begin{array}{l}\text { Survival means interoperability with the likes of Oracle, Informix, Sybase } \\
\text { and Ingres where data can be exchanged at a whim. Pick systems will be } \\
\text { sold off within } 5 \text { years [25]. }\end{array}$ \\
\hline $\begin{array}{l}\text { Frank } \\
\text { Gibb }\end{array}$ & $\begin{array}{l}\text { Blue Circle } \\
\text { Southern } \\
\text { Cement }\end{array}$ & $\begin{array}{l}\text { The Pick operating system will disappear and the DBMS legend will } \\
\text { include SQL support and perhaps a port into Latin language and hosting } \\
\text { on a games console [26]. }\end{array}$ \\
\hline $\begin{array}{l}\text { John } \\
\text { Buchanan }\end{array}$ & $\begin{array}{l}\text { Triad } \\
\text { Software }\end{array}$ & $\begin{array}{l}\text { The three prongs of Open Systems - portability, scalability and } \\
\text { interoperability. SQL compliance and seamless integration with new } \\
\text { products such as an Excel spreadsheet [27]. }\end{array}$ \\
\hline
\end{tabular}

${ }^{8}$ MRP: Materials and Resource Planning. Precursors to modern ERP packages. 
Table 2. (Continued)

\begin{tabular}{|c|c|c|}
\hline Identity & Company & Views \\
\hline $\begin{array}{l}\text { Barry } \\
\text { Churchill }\end{array}$ & NRMA & $\begin{array}{l}\text { Pick must employ the principles of TQM in continually addressing } \\
\text { seamless integration with today's (1992) technology. Pick needs to listen } \\
\text { to its users to understand what their needs are. After all, it's the "users" } \\
\text { who will buy the business systems [28]. }\end{array}$ \\
\hline $\begin{array}{l}\text { Bob } \\
\text { Highland }\end{array}$ & $\begin{array}{l}\text { General } \\
\text { Automation }\end{array}$ & $\begin{array}{l}\text { Coexistence with LANs such as Novell's IPX. Pick should make sure that } \\
\text { it is interoperable with ubiquitous PCs and other workstations [29]. }\end{array}$ \\
\hline $\begin{array}{l}\text { Alan } \\
\text { Glassman }\end{array}$ & BIX & $\begin{array}{l}\text { Pick needed to be ported to the 'state-of-the-art' 3270/RJE and HASP } \\
\text { protocols. Microsoft to re-introduce command line for Windows/LANMan } \\
\text { and Client/Server systems. ADDS terminal division releases a toast-r-oven } \\
\text { connection to their } 9000 \text { series terminal [30]. }\end{array}$ \\
\hline
\end{tabular}

The recurring themes from the Pick community were that Pick as an operating system was doomed and that Unix was to be the host of the future. Interoperability with the burgeoning PC marketplace and other systems $\left(\mathrm{RDBMS}^{9}\right)$ was the next theme followed by the emerging industry standards such as SQL. Networking was addressed by some and its relative low profile in these discussions indicated how little the Pick community thought about TCP/IP, LANs and distributed databases.

\subsection{Pick's Popularity}

During the 1980's through to Y2K Pick boasted that it had more business solutions available than any other environment. There was even a publication called "The Business Software Catalog" that detailed over 3,000 such business applications [31]. The vast library of systems written in Pick/BASIC could be ported from single user machines through to high-end symmetric multi-processors with redundant non-stop capabilities supporting thousands of real-time users.

By this time there were numerous flavours of the Pick environment available. They are detailed in the appendix which illustrates clearly the competition in the Pick community. In addition there were several integrated development environments based on Pick called fourth generation languages (4GL) or $\mathrm{CASE}^{10}$ tools that ranged from elementary program generators such as Wizard ${ }^{11}$ to truly configuration and data driven enterprise-class engines such as Cuebic ${ }^{12}, \mathrm{SB}+{ }^{13}$ and $\mathrm{Posh}^{14}$.

In the 1990's it was not uncommon for an organization to identify a software solution that it needed and to purchase (separately) the hardware platform upon which to mount an operating system (such as Unix), a version of Pick (such as Universe), a 4GL (such as Posh) and the accounting, finance and HR system written in Posh. The average $\mathrm{CFO}$ could not understand why it was not possible to get everything from one

9 RDBMS: Relational Database Management System.

${ }^{10}$ CASE: Computer Aided Software Engineering.

11 Wizard: An early program generator that "created" PICK/Basic code from user entered parameters to describe transaction processes against Pick databases.

${ }^{12}$ Cuebic: A name alluding to the three dimensional nature of the Pick data model.

${ }^{13} \mathrm{SB}+$ : System Builder plus.

${ }^{14}$ Posh: An acronym for "Port Out Starboard Home", the preferred window allocation on transAtlantic boat trips. The name was adopted by its designer and developer Warren Dickins, a boating enthusiast. 
shop on the one invoice, like with an IBM solution. There was great end user flexibility in the choices available and numerous vendors each able to supply the "perfect solution'. The competition was consequently brisk and in high value cases, immensely pressured. The various 'Pick' vendors robustly vied with each other for the prize of the Operating System licence that was often tied to a hardware platform because of the limited ports made by that vendor.

The other edge of the sword was that when errors or difficulties arose it was often difficult to identify the culprit - hardware, operating system, DBMS, 4GL or applications software and it was not uncommon for each to blame the other.

As the Y2K event approached, the 'mainstream' RDBMS community was mounting a major marketing campaign guaranteeing $\mathrm{Y} 2 \mathrm{~K}$ compliance and promising many years of trouble-free use with their "best of breed" and "world's best practice" products. This idea appealed to many "C" level executives and a lot of organisations who were struggling with COBOL, RPGII and PL/1-based systems elected to adopt typically SAP or Oracle solutions.

There was comfort in conforming to peer group pressure that was vigorously supported by so many seemingly knowledgeable people in so many forums. After all, if everyone was going that way then surely everyone can't be wrong?

\subsection{What Changed?}

On Saturday January $1^{\text {st }} 2000$ the world did not end, electricity kept coming out of power points, water flowed as did gas. The IT community rejoiced in their collective wisdom and ability to prevent the disasters that were predicted. However, a number of important new influences or orthodoxies had emerged and had taken root...

- Alignment between cost and value and quality

- The acceptance of products such as Oracle and SAP and their million dollar price tags by financial controllers seeking Y2K immunity

- How can something costing $\$ 150 \mathrm{k}$ be possibly as good as something costing $\$ 1.5 \mathrm{~m}$ ?

- Microsoft establishes universal acceptability of faulty software

- The now infamous EULA states unequivocally that the software you have bought is not guaranteed to work...

- A new corporate jargon emerges

- Multi-million dollar applications from Europe and the USA with labels such "best of breed", "world's best practice" and "enterprise class"

- Would you be brave enough to argue against a product solution that was "acknowledged the best of breed" for your industry sector?

- Decision making on IT acquisitions went from the IT people to the accountants

- Accountants who have now been liberated from their IT departments are now calling the shots on high value IT decisions

- There is a growing atmosphere of suspicion about the justifiability of the huge $\mathrm{Y} 2 \mathrm{~K}$ expenditures [32]

- The Windows GUI is the only practical user interface to a computer

- The Internet (and TCP/IP) is now the accepted data communications orthodoxy

- Safety in numbers 
- In the older days, nobody was ever sacked for buying IBM

- Corporate leaders meet and compare notes about their respective IT solutions

- Universities control the corporate thinking

- Thousands of graduates have only ever been exposed to the Codd relational model and cannot conceive of other models

- Students are increasingly educated using artificial business models that neatly fit their relational toolkits and avoid real-world complexity

The Pick community was certainly not united. Even the local Victorian IPUA attempted to assuage their vendors' sensibilities by renaming themselves to the "Multi Dimensional Database Forum" to remove the word "Pick" from the association name. Few licencees embraced TCP/IP and fewer still acknowledged SQL and interoperability, and those that did make such an investment ensured that it remained proprietary and certainly not portable to other Pick vendors.

\section{Conclusions}

The Pick community's inability to work together on keeping up with technology will be one of the reasons that many organisations will be electing to drop Pick as their preferred business platform and select more expensive mainstream solutions.

There were some efforts to create a Windows-based front end but it came to nothing as funding was limited to one vendor. It is also my own opinion that industry was so used to the two dimensional database model that interfaces tended to mirror the spreadsheet in concept. Pick's data model being inherently three (or even four) dimensional was difficult to effectively represent with the tools of the day. It is of passing interest that today's advanced HTML is now capable of such a representation without too much difficulty.

It is also curious to note that no popular operating system has been named after its inventor. Had PickOS been named something like OSMV (OS Multi-value) then a lot of criticism might have been avoided, and many days in the California Superior Court likewise avoided. And had Dick Pick named his programming language similarly after the famous courtesans like Pascal and Ada, perhaps something like "Zion" might have reduced the criticisms of the language name. But it is perception that matters today and perception is reality. Perception is a controlled substance and today the accepted orthodoxies are Windows point and click, Internet, Unix, rigorous Codd relational model and it just has to be "world's best practice", whatever that means. With accountants independently making the key decisions today, businesses are happy to change their business models and processes to align with some "best" standard from Europe or America as manifested in a small selection of "Enterprise" systems. Thanks to the largest software manufacturer in the world, it doesn't necessarily have to work entirely properly either.

\section{References}

1. Gadamer, H.-G. (ed.): The Historicity of Understanding. Critical Sociology, Selected Readings, Connerton, P. (ed.). Penguin Books Ltd., Harmondsworth (1976)

2. Gadamer, H.-G.: Truth and Method, 3rd edn. Continuum, London (2004)

3. Forrester, C.: Interview (2010)

4. Hewlett-Packard, MPE-IV Software Pocket Guide. Hewlett Packard, Cupertino (1981) 
5. Brooks, F.P.: Mythical Man Month. Addison-Wesley, Reading (1975)

6. Denning, P.J.: The working set model for program behavior. Communications of the ACM 11(5), 323-333 (1968)

7. Rodstein, H.E.: Pick For Professionals - Advanced Methods and Techniques. In: Sisk, J.E. (ed.) The Pick Library. TAB Professional and Reference Books, Blue Ridge Summit (1990)

8. Martin, J.: Computer Database organization, 1st edn. Prentice-Hall Inc., Englewood Cliffs (1975)

9. Volokh, E.: Relational Databases vs IMAGE: What the Fuss is all About, in Interex, Detroit (1986)

10. Codd, E.F.: A relational model of data for large shared data banks. ACM Commun. 13(6), 377-387 (1970)

11. Codd, E.F.: Extending the database relational model to capture more meaning. ACM Trans. Database Syst. 4(4), 397-434 (1979)

12. Codd, E.F.: The relational model for database management: version 2, p. 567. AddisonWesley Longman Publishing Co., Inc., Amsterdam (1990)

13. RMIT, Advanced College Handbook. RMIT Advanced College, Melbourne (1985)

14. Tsichritzis, D.C., Lochovsky, F.H.: Data Models. Prentice-Hall, Inc., Englewood Cliffs (1982)

15. Brinton, J.B.: New minis push into power era. In: Electronics (1979)

16. Wade, L.: Superminis: Evolution or quantum jump. In: Digital Design (1979)

17. Giobbi, G.: Pick Down Under. News and Review, Los Angeles (1992)

18. Fenwick, P.: New Directions in Information Technology. In: Pick-Up. International Pick Users Association (NSW), Neutral Bay (1992)

19. Coulson, R.: The Future of PIK in Australia. In: Pick-Up. International Pick Users Association (NSW), Neutral Bay (1992)

20. Leister, T.: Where is Pick Going? In: Pick-Up. International Pick Users Association (NSW), Neutral Bay (1992)

21. Couvret, T.: Pick - the Next 10 Years. In: Pick-Up. International Pick Users Association (NSW), Neutral Bay (1992)

22. Maggi, A.D.: Pick - From Proprietary to open Systems. In: Pick-Up. International Pick Users Association (NSW), Neutral Bay (1992)

23. Cave, C.: Where is Pick Heading? In: Pick-Up. International Pick Users Association (NSW), Neutral Bay (1992)

24. Cianchi, T.: Will Pick (and the software business as we know it) Survive? In: Pick-Up. International Pick Users Association (NSW), Neutral Bay (1992)

25. Ferris, M.: Where is Pick Headed in the Next 5-10 Years? In: Pick-Up. International Pick Users Association (NSW), Neutral Bay (1992)

26. Gibb, F.: Pick Beyond 2000 - Back to the Future. In: Pick-Up. International Pick Users Association (NSW), Neutral Bay (1992)

27. Buchanan, J.: Whither Pick or Wither Pick? In: Pick-Up. International Pick Users Association (NSW), Neutral Bay (1992)

28. Churchill, B.: The future of Pick - a User's View. In: Pick-Up. International Pick Users Association (NSW), Neutral Bay (1992)

29. Highland, B.: Whither Pick in the 90's? In: Pick-Up. International Pick Users Association (NSW), Neutral Bay (1992)

30. Glassman, A.: Predictions for 1992. In: Pick-Up. International Pick Users Association (NSW), Neutral Bay (1992)

31. IDBMA, Industry Impact Study - the Pick Marketplace. International Database Management Association Inc., San Diego (1989)

32. Lukaitis, S.: The key issues that impact on the successful alignment of business and its IT function, in Department of Information Systems. Melbourne, Deakin (2010) 
6 Appendix Various Incarnations of Pick over the Years

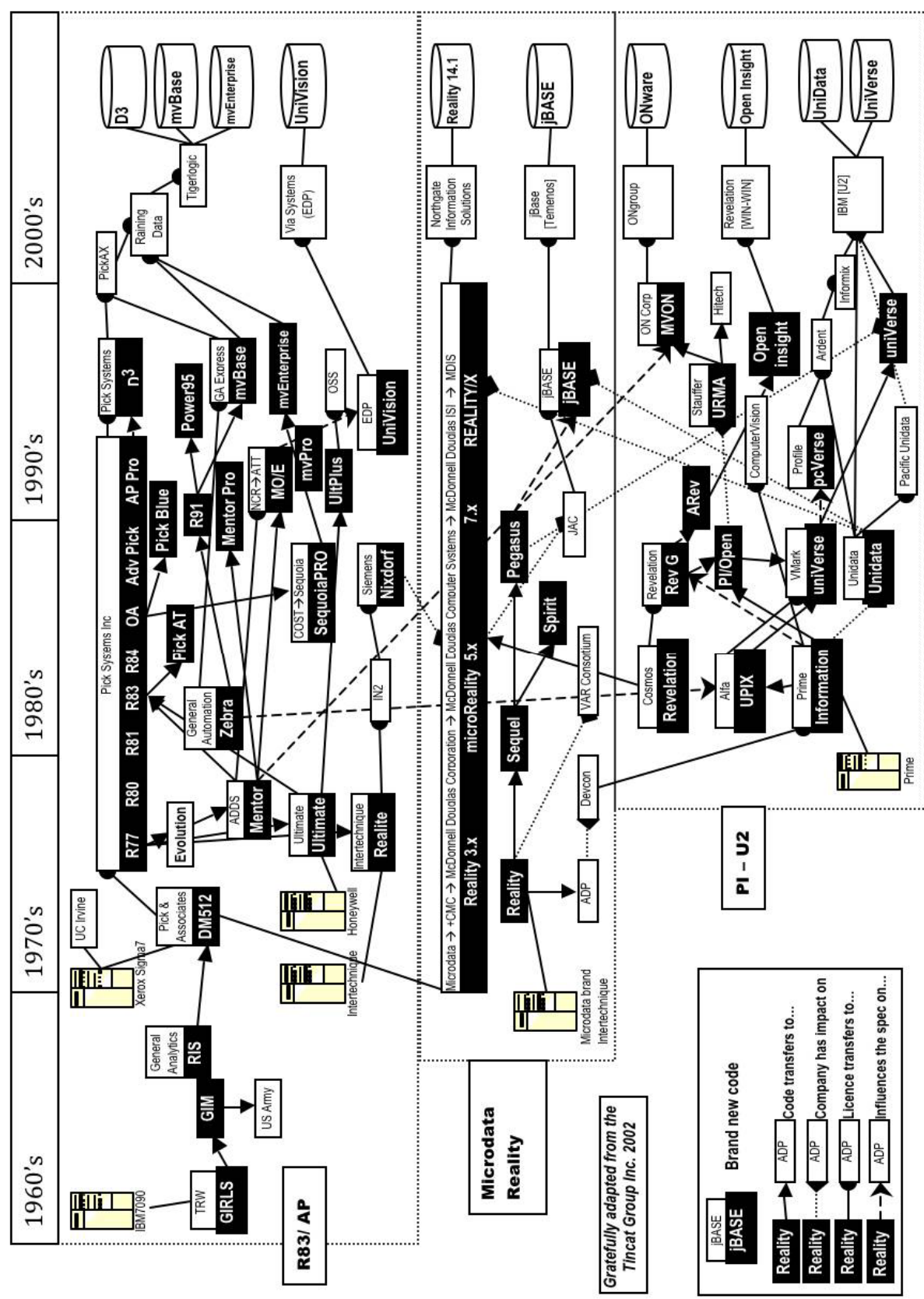

